\title{
Mastocytosis and systemic sclerosis: a clinical association
}

\author{
Gianluca Bagnato ${ }^{1}$, William Neal Roberts ${ }^{2}$, Davide Sciortino ${ }^{1}$, Donatella Sangari ${ }^{1}$, Santa Cirmi ${ }^{3}$, \\ Roneka L. Ravenell ${ }^{2}$, Michele Navarra ${ }^{3}$, Gianfilippo Bagnato ${ }^{1}$ and Sebastiano Gangemi ${ }^{4,5^{*}}$
}

\begin{abstract}
Background: Systemic sclerosis (SSC) is a complex autoimmune disease characterized by vascular alterations and autoimmune activation leading to widespread organ fibrosis. At the early stage of disease when organ involvement and extent of disease are emerging, mast cells may have some role, as implied by both symptoms and histologic evidence.

Case presentation: A female patient diagnosed with cutaneous mastocytosis experienced the onset of systemic sclerosis after 15 years followed by the switch of mastocytosis to the systemic phenotype. A literature review on the evidences related to mast-cells activation in systemic sclerosis is presented below.

Conclusions: For clinicians, more attention must be paid to the potential association between systemic sclerosis and cancer. This case suggests that a proliferative disease in the mast cell compartment-though representing a rare association - may not be completely unexpected in SSc and perhaps excess mast cell activity can serve a pathogenic role in promoting fibrotic disease.
\end{abstract}

Keywords: Mastocytosis, Systemic sclerosis, Mastcells, Fibrosis

\section{Background}

Systemic sclerosis (SSc) is a connective tissue disorder characterized by autoimmune activation and endothelial dysfunction leading to fibrotic changes of the skin and internal organs [1]. The clinical presentation of this disease is highly heterogeneous. In addition, prediction of the ultimate pattern of specific internal organ involvement, as well as the development of overlap features, is difficult at the time of the diagnosis [2]. Early in the course, patients with SSc skin disease report pruritus, being described frequently as the most bothersome symptom [3-5]. Among 400 patients, $45 \%$ reported pruritus with a disease duration of at least 1 year, increasing to $69 \%$ when considering only patients with $1-2$ years of disease duration [6]. Lip biopsy in very early stages of SSc reveals that mast cell infiltration starts before the disease

\footnotetext{
*Correspondence: gangemis@unime.it

${ }^{4}$ School and Division of Allergy and Clinical Immunology, Department of Clinical and Experimental Medicine, University of Messina, Messina, Italy

Full list of author information is available at the end of the article
}

acquires definite features [7]. Biopsy of involved skin of SSc patients confirms that mast cells (MC) reside in proximity of fibroblasts, produce TGF- $\beta$ and the number of degranulated cells is particularly increased [8]. More specifically, the MCT (tryptase-positive, chymase-negative) are more prominent in SSc lesional skin compared to MCTC (tryptase-positive, chymase-positive) type of mast cell that represents the normal population of mast cell in healthy subjects [9].

Nevertheless, it remains unclear whether the switch toward a specific population of MC favours fibroblast proliferation through the release of tryptase, but it might. The early phase of SSC includes interstitial oedema and pruritus, the corticosteroid responsive so-called "puffy hands" phase of SSc clinically. Mast cell mediator release may promote the early phase of interstitial oedema and pruritus through histamine and the processing of bigendothelin in endothelium through chymase, as evidenced in rat lungs. On the other hand, mast cells can also counteract collagen deposition through matrix metalloproteinase activation [10]. 
Although mastocytosis is rare in any setting, the incidence of malignancy in general in SSc is increased compared to the general population (pooled standardized incidence ration 1.41 for all cancers). The incidence of cancer is higher within the first 12 months after the initial SSc diagnosis [11]. In population-based studies of SSc patients, it has been reported that the hematologic malignancies are primarily non-Hodgkin lymphomas and leukemias [12], and in female subjects hematologic cancer is more frequent [13]. Consequently, a proliferative disease in the mast cell compartment-though representing a rare association-may not be completely unexpected in SSc. In this report, we call attention to a case of patient who developed SSc after, rather than before, a diagnosis of cutaneous mastocytosis, and in whom the mastocytosis became more extensive after the SSc became manifest.

\section{Case presentation}

A 36 year-old woman presented with complaints of dysphagia, fatigue, widespread pain and muscle weakness localized mainly at the inferior limbs. Fifteen years prior, she was diagnosed with cutaneous mastocytosis, confirmed by skin biopsy. Over the 6 months, she noticed worsening of Raynaud's phenomenon and thickening of the skin over the hands and feet. She underwent videocapillaroscopy revealing an active scleroderma pattern and was diagnosed with systemic sclerosis. Laboratory test showed ANA positivity with high titers (1:2560, granular pattern) and anti-SSa. Four months later, she was admitted to the hospital due to worsening dysphagia, fatigue and muscle weakness.

Clinical examination revealed body temperature $36.5{ }^{\circ} \mathrm{C}$, blood pressure $127 / 80 \mathrm{mmHg}$ and a regular pulse of 76 beats/min. No superficial lymph adenopathy was evident. Skin thickening (Rodnan skin score 28/51) and spleen enlargement were noted, however. Laboratory tests revealed that rheumatoid factor, as well as anti-SSB, anti-Sm, anti-Scl-70, anti-centromere, anti-Jo1 and anti-DNA antibodies were all negative. Serum levels of CK 350 U/L (n.v.197 U/L), LDH 652 U/L (n.v. 200 U/L), myoglobin (421 ng/mL n.v. 0-70 ng/mL), SGOT $47 \mathrm{U} / \mathrm{L}$ (n.v. $29 \mathrm{U} / \mathrm{L}$ ), SGPT $71 \mathrm{U} / \mathrm{L}$ (n.v. $51 \mathrm{U} / \mathrm{L}$ ) were elevated. The serologic HLA typing was A1, B51 and CW7 for class I and DQ7, DR11 and DR52 for class II.

Ultrasound examination of the spleen confirmed the physical examination finding. Echocardiographic examination was relevant for an increase in pulmonary arterial pressure $(40 \mathrm{mmHg})$. Due to the suspicion of the onset of a systemic mastocytosis, based on the involvement of the spleen and vertebral pain, the patient underwent bone marrow biopsy, PET and total body CT. Bone marrow biopsy result confirmed an intense infiltration of mast cells triptase + , CD25+ , CD117+ , CD123+ , CD45RB/ LCA+ , CD68+ , CD14 \pm ,CD20-, CD30-. PET scan showed thoracic and abdominal lymph nodes, spleen and sacrum uptake. CT scan detected widespread lytic lesion of the chest and vertebral bones, basilar reticulonodular infiltrates, and spleen enlargement. Electromyography was compatible with an inflammatory myopathy.

The patient started therapy with prednisone at the dose of $50 \mathrm{mg}$ day, nifedipine $10 \mathrm{mg}$ day, mycophenale mofetil at the dose of $2 \mathrm{~g}$ day and iloprost infusions $0.05 \mathrm{mg}$ every day per 3 days every month. She underwent full evaluation in a heamotologic center located in a different hospital, and received zoledronic acid for osteolytic lesions. After 2 months, the patient's myalgias and fatigue improved, as confirmed by serology, as well as her vertebral pain. The addition of a chemotherapeutic agent for systemic mastocytosis is now under consideration.

\section{Conclusions}

A previous case series study described this rare association in which systemic sclerosis precedes the onset of cutaneous mastocytosis [14], perhaps suggesting some underlying stimulation of the mast cell compartment as a feature of the SSc. The investigators reported two cases of skin lesions associated with mast-cell infiltrates compatible with the diagnosis of cutaneous mastocytosis at 30 and 6 years after the onset of SSc. In contrast, in our case, the initial cutaneous mastocytosis has an interplay with SSc in which cutaneous mastocytosis precedes the onset of systemic sclerosis, perhaps suggesting that excess mast cell activity can serve a pathogenic role in promoting fibrotic disease. The onset of SSc in this case in turn was subsequently accompanied by the progression of the cutaneous form of mastocytosis into the widespread systemic phenotype. This case therefore raises the possibility that, the link between mast cell activity and fibrotic disease may ultimately be understood as a bidirectional one, or a feedback loop.

Several lines of evidence support the involvement of mast-cells in the pathogenesis of SSc $[15,16]$ : in the tight skin mouse model of SSc the proliferation and activation of mast-cells leads to augmentation of fibrosis; an increase of dermal mast cell density is typical of the early phase of the disease [17]; mast cells are involved in the development of interstitial oedema [18]; the degranulation of mast-cells is considered one of the mechanisms leading to TGF- $\beta$ secretion in SSc [19]. Indeed, mast cells granules contain several profibrotic moelcules, such as TGF- $\beta$ itself and also PDGF and VEGF, plus other molecules that favour myofibroblast transdiferrentiation, such as IL-4 and GM-CSF [20].

Of note, among the chemotherapeutic agents available for the treatment of mastocytosis, a small tyrosine 
kinase inhibitor, imatinib mesylate, has indications for specific forms of this malignancy (without the D816 V c-Kit mutation or with c-Kit mutational status unknown) [21] though it failed in SSC [22]. Similarly, in SSc another related tyrosine kinase inhibitor, nintedanib, has gained increasing attention as a potential therapeutic agent in interstitial pulmonary fibrosis. Promising results have been reported in animal models [23] and in clinical trials related to skin fibrosis and lung function [24]. Nintedanib is now in clinical trial for ILD due to SSc. If tyrosine kinase inhibitors are found to play a role in therapeutic regimens aimed at fibrotic diseases such as idiopathic pulmonary fibrosis (IPF) and systemic sclerosis associated interstitial lung disease (SSc-ILD), it may be that they work in part by inhibition of slower, chronic, non-anaphylactic transdegraulation of mast cells, among other mechanisms.

\begin{abstract}
Abbreviations
SSc: systemic sclerosis; MC: mastcells; MCT: mast cells tryptase-positive chymase-negative; MCTC: mast cells tryptase-positive chymase-positive; ANA: antinuclear antibodies; anti-SS-A: anti-Sjögren's-syndrome-related antigen A; anti-SS-B: anti-Sjögren's-syndrome-related antigen B; anti-Sm: anti-Smith antibodies; anti-SCl-70: anti-topoisomerase I antibodies; anti-J01: anti-intracellular enzyme histidyl tRNA synthetase antibodies; CK: creatine kinase; LDH: lactate dehydrogenase; SGOT: serum glutamic-oxaloacetic transaminase; SGPT: serum glutamic-pyruvic transaminase; HLA: human leukocyte antigen; CT: computerized tomography; CD: cluster of differentiation; PET: positron emission tomography; TGF- $\beta$ : transforming growth factor $\beta$; PDGF: platelet-derived growth factor; VEGF: vascular endothelial growth factor; IL-4: interleukin-4; GM-CSF: granulocyte-macrophage colony-stimulating factor; IPF: idiopathic pulmonary fibrosis; SSc-ILD: systemic sclerosis associated interstitial lung disease; c-kit: tyrosine-protein kinase kit.
\end{abstract}

\section{Authors' contributions}

GLB, DAS, DOS collected patient data. WNR, RR and SC contributed to literature search and to the writing of the manuscript. SG, MN and GFB provided the final revision of the manuscript, GLB, WNR and RR revised the language. All authors read and approved the final manuscript.

\section{Author details \\ ${ }^{1}$ Division of Rheumatology, Department of Clinical and Experimental Medicine, University of Messina, Messina, Italy. ${ }^{2}$ Division of Rheumatol- ogy, Department of Medicine, University of Louisville, Louisville, KY, USA. ${ }^{3}$ Department of Chemical, Biological, Pharmaceutical and Environmental Sciences, University of Messina, Messina, Italy. ${ }^{4}$ School and Division of Allergy and Clinical Immunology, Department of Clinical and Experimental Medicine, University of Messina, Messina, Italy. ${ }^{5}$ Institute of Applied Sciences and Intel- ligent Systems (ISASI), Pozzuoli, NA, Italy.}

\section{Acknowledgements}

Not applicable.

\section{Competing interests}

The authors declare that they have no competing interests.

\section{Availability of data and materials}

The datasets during and/or analysed during the current study available from the corresponding author on reasonable request.

\section{Consent for publication}

The patient gave her consent to the use of the data obtained from the diagnostic procedures for scientific research.
Received: 2 August 2016 Accepted: 3 October 2016

Published online: 11 October 2016

\section{References}

1. Desbois AC, Cacoub P. Systemic sclerosis: an update in 2016. Autoimmun Rev. 2016;15(5):417-26.

2. Walker UA, Tyndall A, Czirják L, Denton C, Farge-Bancel D, Kowal-Bielecka O, Müller-Ladner U, Bocelli-Tyndall C, Matucci-Cerinic M. Clinical risk assessment of organ manifestations in systemic sclerosis: a report from the EULAR scleroderma trials and research group database. Ann Rheum Dis. 2007;66(6):754-63.

3. Mayes MD. The scleroderma book: a guide for patients and families. New York: Oxford University Press; 1999.

4. Steen VD. Clinical manifestations of systemic sclerosis. Semin Cutan Med Surg. 1998;17:48-54.

5. Connolly MK. Scleroderma. Dermatol Ther. 2001;14:81-94.

6. Razykov I, Thombs BD, Hudson M, et al. Prevalence and clinical correlates of pruritus in patients with systemic sclerosis. Arthritis Care Res. 2009;61:1765-70.

7. Hebbar M, Gillot JM, Hachulla E, Lassalle P, Hatron PY, Devulder B, Janin A. Early expression of E-selectin, tumor necrosis factor alpha, and mast cell infiltration in the salivary glands of patients with systemic sclerosis. Arthritis Rheum. 1996;39(7):1161-5.

8. Hügle T, Hogan V, White KE, van Laar JM. Mast cells are a source of transforming growth factor $\beta$ in systemic sclerosis. Arthritis Rheum. 2011;63(3):795-9.

9. Irani AM, Gruber BL, Kaufman LD, Kahaleh MB, Schwartz LB. Mast cell changes in scleroderma. Presence of MCT cells in the skin and evidence of mast cell activation. Arthritis Rheum. 1992;35(8):933-9.

10. Akimoto S, Ishikawa O, Igarashi Y, Kurosawa M, Miyachi Y. Dermal mast cells in scleroderma: their skin density, tryptase/chymase phenotypes and degranulation. Br J Dermatol. 1998;138(3):399-406.

11. Onishi A, Sugiyama D, Kumagai S, Morinobu A. Cancer incidence in systemic sclerosis: meta-analysis of population-based cohort studies. Arthritis Rheum. 2013;65(7):1913-21.

12. Olesen AB, Svaerke C, Farkas DK, Sørensen HT. Systemic sclerosis and the risk of cancer: a nationwide population-based cohort study. Br J Dermatol. 2010;163(4):800-6.

13. Kuo CF, Luo SF, Yu KH, Chou IJ, Tseng WY, Chang HC, Fang YF, Chiou MJ, See LC. Cancer risk among patients with systemic sclerosis: a nationwide population study in Taiwan. Scand J Rheumatol. 2012;41(1):44-9.

14. Frigui M, Dupin N, Carlotti A, Bussone G, Pestre V, Charles P, Crabol Y, Bérezné A, Guillevin L, Mouthon L. Telangiectasic mastocytosis with systemic sclerosis. Presse Med. 2013;42(5):902-4.

15. Bagnato $G$, Harari S. Cellular interactions in the pathogenesis of interstitial lung diseases. Eur Respir Rev. 2015;24(135):102-14.

16. Yukawa S, Yamaoka K, Sawamukai N, Shimajiri S, Saito K, Tanaka Y. Involvement of mast cells in systemic sclerosis. Nihon Rinsho Meneki Gakkai Kaishi. 2010;33(2):81-6.

17. Yukawa S, Yamaoka K, Sawamukai N, Shimajiri S, Kubo S, Miyagawa I, Sonomoto K, Saito K, Tanaka Y. Dermal mast cell density in fingers reflects severity of skin sclerosis in systemic sclerosis. Mod Rheumatol. 2013;23(6):1151-7.

18. Akimoto S, Ishikawa O, Igarashi Y, Kurosawa M, Miyachi Y. Dermal mast cells in scleroderma: their skin density, tryptase/chymase phenotypes and degranulation. Br J Dermatol. 1998;138(3):399-406.

19. Hügle T, Hogan V, White KE, van Laar JM. Mast cells are a source of transforming growth factor $\beta$ in systemic sclerosis. Arthritis Rheum. 2011;63(3):795-9.

20. Hügle T. Beyond allergy: the role of mast cells in fibrosis. Swiss Med Wkly. 2014;3(144):w13999.

21. Vega-Ruiz A, Cortes JE, Sever M, Manshouri T, Quintás-Cardama A, Luthra R, Kantarjian HM, Verstovsek S. Phase II study of imatinib mesylate as therapy for patients with systemic mastocytosis. Leuk Res. 2009;33(11):1481-4.

22. Denton CP, Merkel PA, Furst DE, Khanna D, Emery P, Hsu VM, Silliman N, Streisand J, Powell J, Akesson A, Coppock J, et al. Cat-192 Study Group; 
Scleroderma Clinical Trials Consortium. Recombinant human antitransforming growth factor beta 1 antibody therapy in systemic sclerosis: a multicenter, randomized, placebo-controlled phase I/II trial of CAT-192. Arthritis Rheum. 2007;56(1):323-33.

23. Akhmetshina A, Venalis P, Dees C, Busch N, Zwerina J, Schett G, Distler O, Distler JH. Treatment with imatinib prevents fibrosis in different preclinical models of systemic sclerosis and induces regression of established fibrosis. Arthritis Rheum. 2009;60(1):219-24.
24. Fraticelli P, Gabrielli B, Pomponio G, Valentini G, Bosello S, Riboldi P, Gerosa M, Faggioli P, Giacomelli R, Del Papa N, Gerli R, Lunardi C, Bombardieri S, Malorni W, Corvetta A, Gabrielli A, Moroncini G. Imatinib in Scleroderma Italian Study Group. Low-dose oral imatinib in the treatment of systemic sclerosis interstitial lung disease unresponsive to cyclophosphamide: a phase II pilot study. Arthritis Res Ther. 2014;16(4):R144. doi:10.1186/ ar4606.

\section{Submit your next manuscript to BioMed Central and we will help you at every step:}

- We accept pre-submission inquiries

- Our selector tool helps you to find the most relevant journal

- We provide round the clock customer support

- Convenient online submission

- Thorough peer review

- Inclusion in PubMed and all major indexing services

- Maximum visibility for your research

Submit your manuscript at

www.biomedcentral.com/submit 